\title{
Neocortical Inhibitory Terminals Innervate Dendritic Spines Targeted by Thalamocortical Afferents
}

\author{
Yoshiyuki Kubota, Sayuri Hatada, Satoru Kondo, Fuyuki Karube, and Yasuo Kawaguchi \\ Division of Cerebral Circuitry, National Institute for Physiological Sciences, Okazaki, Aichi 444-8787, Japan
}

Fast inhibition in the cortex is gated primarily at GABAergic synapses formed by local interneurons onto postsynaptic targets. Although GABAergic inputs to the somata and axon initial segments of neocortical pyramidal neurons are associated with direct inhibition of action potential generation, the role of GABAergic inputs to distal dendritic segments, including spines, is less well characterized. Because a significant proportion of inhibitory input occurs on distal dendrites and spines, it will be important to determine whether these GABAergic synapses are formed selectively by certain classes of presynaptic cells onto specific postsynaptic elements. By electron microscopic observations of synapses formed by different subtypes of nonpyramidal cells, we found that a surprisingly large fraction $(33.4 \pm 9.3 \%)$ of terminals formed symmetrical synaptic junctions onto a subset of cortical spines that were mostly coinnervated by an asymmetrical terminal. Using VGLUT1 and VGLUT2 isoform of the glutamate vesicular transporter immunohistochemistry, we found that the double-innervated spines selectively received thalamocortical afferents expressing the VGLUT2 but almost never intracortical inputs expressing the VGLUT1. When comparing the volumes of differentially innervated spines and their synaptic junction areas, we found that spines innervated by VGLUT2-positive terminal were significantly larger than spines innervated by VGLUT1-positive terminal and that these spines had larger, and more often perforated, synapses than those of spines innervated by VGLUT1-positive afferent. These results demonstrate that inhibitory inputs to pyramidal cell spines may preferentially reduce thalamocortical rather than intracortical synaptic transmission and are therefore positioned to selectively gate extracortical information.

Key words: cortex; spine; synapse; thalamocortical afferent; VGLUT; nonpyramidal cell

\section{Introduction}

Cortical microcircuit is composed of excitatory pyramidal and inhibitory nonpyramidal cells with different kinds of afferent fibers, intracortical and thalamocortical fibers and so on. Information processing in the cerebral cortex is highly regulated by inhibitory input from GABAergic interneurons, which are a diverse population, that appropriately gate information flow during periods of enhanced network activity (Kawaguchi and Kubota, 1993, 1997; Somogyi et al., 1998; Kawaguchi and Kondo, 2002; Thomson et al., 2002; Klausberger et al., 2003, 2004, 2005; Markram et al., 2004; Yoshimura and Callaway, 2005; Yoshimura et al., 2005). Recent advances have demonstrated that, in addition

Received Sept. 5, 2006; revised Dec. 21, 2006; accepted Dec. 21, 2006.

This work was supported by a grant-in-aid for scientific research from the Ministry of Education, Culture, Sports, Science, and Technology of Japan and the Ministry of Health, Labor, and Welfare of Japan. We thank Drs. A. T. Gulledge and P. Somogyi for comments on this manuscript, Dr. T. Kaneko for the VGLUTs antiserums, Dr. J.-M. Fritschy for the $\mathrm{GABA}_{\mathrm{A}} \alpha 1$ subunit antiserum, Dr. A. Watakabe for ROR $\beta$ for in situ hybridization experiment, and Dr. Y. Fukazawa for advices in postembedding immunohistochemistry. We thank Drs J. J. Lambert, T. Rosahl, and D. Belelli at the University of Dundee (Dundee, UK) for providing tissue of the $\alpha 1$ subunit-deficient and control mice and Dr. Jojanneke Huck at the Medical Research Council Anatomical Neuropharmacology Unit at Oxford University (Oxford, UK) for fixing the brains. We thank Y. Itoh, M. Saito, K. Suzuki, and S. Kato for technical assistance.

Correspondence should be addressed to Dr. Yoshiyuki Kubota, Division of Cerebral Circuitry, National Institute for Physiological Sciences, 5-1 Myodaiji-Higashiyama, 0kazaki, Aichi 444-8787, Japan. E-mail: yoshiy@nips.ac.jp.

S. Kondo's present address: Department of Cell Biology, School of Medicine, Tokyo Medical and Dental University, Tokyo 113-8519, Japan.

F. Karube's present address: Laboratory for Cortical Systems Neuroscience, Department of Anatomy, Histology, and Embryology, Debrecen University, 4012 Debrecen, Hungary.

D01:10.1523/JNEUROSCI.3846-06.2007

Copyright $\odot 2007$ Society for Neuroscience $\quad$ 0270-6474/07/271139-12\$15.00/0 to being diverse in their physiological and morphological properties, neocortical interneurons are highly selective in choosing postsynaptic targets (Támas et al., 1997, 2003; Kawaguchi and Kubota, 1998; Watts and Thomson, 2005). Whereas some axon terminals of interneurons provide inhibition to somatic and proximal dendritic regions of neocortical pyramidal neurons, other GABAergic axons target distal dendritic processes, including spines. Approximately $25 \%$ of GABAergic axon terminals contact spines (Beaulieu et al., 1992), and some GABA-targeted spines also receive excitatory (asymmetrical) glutamatergic synaptic input (Jones and Powell, 1969; Kisvárday et al., 1987; Dehay et al., 1991; Nusser et al., 1996; Meskenaite, 1997; Knott et al., 2002; Támas et al., 2003). Because dendritic spines are electrically compact and usually innervated by a single excitatory synapse, inhibitory inputs onto spines are in a unique position to gate (or "veto") the impact of individual excitatory inputs to cortical neurons (Dehay et al., 1991). GABAergic synapses occur on only a minority of dendritic spines. Whether these spines are targeted by specific excitatory afferents, intracortical or thalamocortical fibers, has not yet been determined (but see Dehay et al., 1991; Kuroda et al., 2004). By reconstruction of successive ultrathin sections, we analyzed the synaptic inputs on spines in the cortex as well as the targets innervated by nonpyramidal cells. The results suggested that diverse types of GABA cells make a symmetrical synapses with spines that is also innervated by an asymmetrical input and that inhibitory innervation on spines occurs only on those that are also targeted by thalamocortical excitatory inputs, not by intracortical afferents. 


\section{Materials and Methods}

In vitro intracellular filling

Experiments were performed on young Wistar rats (19-23 d postnatal) in accordance with National Institute of Physiological Sciences Animal Care and Use Committee guidelines. Sections of frontal cortex were cut to a thickness of $300 \mu \mathrm{m}$ and immersed in a buffered solution $\left(30-31^{\circ} \mathrm{C}\right)$ containing the following (in $\mathrm{mm}$ ): $124.0 \mathrm{NaCl}, 3.0 \mathrm{KCl}, 2.4 \mathrm{CaCl}_{2}, 1.2$ $\mathrm{MgCl}_{2}, 26.0 \mathrm{NaHCO}_{3}, 1.0 \mathrm{NaH}_{2} \mathrm{PO}_{4}$, and 10.0 glucose (aerated with a mixture of $95 \% \mathrm{O}_{2}$ and $5 \% \mathrm{CO}_{2}$ ). Whole-cell access was obtained in neurons targeted visually using differential interference contrast optics and a $40 \times$ water immersion objective. The pipette solution consisted of the following (in mM): 120 potassium methylsulfate, $5.0 \mathrm{KCl}, 0.5 \mathrm{EGTA}$, $1.7 \mathrm{MgCl}_{2}$, 4.0 Na2ATP, 0.3 NaGTP, 8.5 HEPES, and 17 biocytin. The recording was usually performed for $10-20 \mathrm{~min}$.

\section{Histology and immunohistochemistry}

Slice histology. Tissue slices were fixed by immersion in $4 \%$ paraformaldehyde, 1.25 or $0.05 \%$ glutaraldehyde, and $0.2 \%$ picric acid in a $0.1 \mathrm{M}$ phosphate buffer $(\mathrm{PB})$ at room temperature (RT) and were then exposed to microwave irradiation $(15 \mathrm{~s})$ and postfixed overnight at $4^{\circ} \mathrm{C}$. Tissue was then embedded in $2.5 \%$ agar and $0.25 \%$ agarose gel and resectioned into 50 - $\mu \mathrm{m}$-thick slices

Each slice (a set of $50 \mu \mathrm{m}$ sections after resectioning) was further treated by one of the following two procedures.

(1) Some slices were incubated with avidin-biotin-peroxidase complex (Vector Laboratories, Burlingame, CA) in Tris-HCl-buffered saline (TBS) with or without $0.04 \%$ Triton X-100 (TX), and reacted with 3,3diaminobenzidine tetrahydrochloride (DAB) $(0.05 \%)$ and $\mathrm{H}_{2} \mathrm{O}_{2}$ $(0.003 \%)$.

(2) Other slices were processed for fluorescence immunohistochemistry to identify the neurochemical markers vasoactive intestinal peptide (VIP) and calretinin. The slices were incubated with the primary antibodies: VIP developed in rabbit (1:2000, catalog \#20077; DiaSorin, Stillwater, MN) and calretinin (1:1000, catalog \#6B3; Swant, Bellinzona, Switzerland) in TBS containing $2 \%$ bovine serum albumin, $10 \%$ normal goat or horse serum, and $0.5 \%$ (or $0.04 \%$ ) TX. The slices were incubated in fluorescent secondary antibodies, followed by incubation with Alexa 350 streptavidin (1:200, catalog \#S-11249; Invitrogen, Carlsbad, CA) in TBS. After examination for fluorescence, the slices were incubated with avidin-biotin-peroxidase complex and reacted with $\mathrm{DAB}$ and $\mathrm{H}_{2} \mathrm{O}_{2}$.

Slices were then postfixed in $1 \% \mathrm{OsO}_{4}$ in $\mathrm{PB}$, dehydrated, and flat embedded on silicon-coated glass slides in Epon. Recovered neurons were drawn using a drawing tube or reconstructed three dimensionally using the Neurolucida system (MicroBrightField, Williston, VT) with a $60 \times$ objective lens. After light microscopic (LM) reconstruction, stained cells were photographed using a $100 \times$ objective and serially sectioned into $90 \mathrm{~nm}$ thickness using an ultramicrotome (Reichert Ultracut S). Ultrathin sections mounted on one-hole grids were stained with lead citrate. The thickness of ultrathin sections was calibrated by a color laser three-dimensional (3D) profile microscope (VK-9500; Keyence, Osaka, Japan). Electron micrographs were taken with a Hitachi H-7000 electron microscope (EM), using tilting of up to $60^{\circ}$. EM images of the labeled terminals and associated structures were captured using a CCD camera and reconstructed three dimensionally (Visilog; Noesis, France).

VGLUT immunohistochemistry. Three male Wistar rats (6 weeks old, $140-160 \mathrm{~g}$ ) were used in accordance with National Institute of Physiological Sciences Animal Care and Use Committee guidelines. Animals were anesthetized with an overdose of Nembutal and perfused through the heart with normal saline, followed by $300 \mathrm{ml}$ of $4 \%$ paraformaldehyde containing $0.2 \%$ picric acid and $0.1 \%$ glutaraldehyde in PB. The animals were left for $3 \mathrm{~h}$ at room temperature for postfixation. Brains were then removed, and oblique horizontal sections (50 $\mu \mathrm{m}$ thick) were cut on a vibratome along the line of the rhinal fissure for EM or coronal sections (50 $\mu \mathrm{m}$ thick) for LM observation. Tissue sections were put in glass tubes containing 15\% sucrose in PB for $1 \mathrm{~h}$ and then in 25\% sucrose and $10 \%$ glycerol in $\mathrm{PB}$ for $2 \mathrm{~h}$, frozen with liquid nitrogen, and then thawed at room temperature. The sections were then incubated in $\mathrm{PB}$ containing $1 \%$ sodium borohydrate for $30 \mathrm{~min}$ and in TBS containing $1 \% \mathrm{H}_{2} \mathrm{O}_{2}$ for $30 \mathrm{~min}$ before incubation with primary antiserum against vesicular glutamate transporters VGLUT1 or VGLUT2 (generous gifts from Dr. T. Kaneko, Kyoto University, Kyoto, Japan) in TBS containing $10 \% \mathrm{NGS}$ and $2 \% \mathrm{BSA}$ in $0.05 \mathrm{~m}$ TBS overnight at $4^{\circ} \mathrm{C}$. Then the sections were incubated in biotin-conjugated secondary antiserum followed by $\mathrm{ABC}$ complex and staining with $\mathrm{DAB}$. The stained sections were postfixed for 60 min in $1 \% \mathrm{OsO}_{4}$ in $\mathrm{PB}$ and dehydrated in graded ethanol with $1 \%$ uranyl acetate at the $70 \%$ ethanol dehydration state. Sections were flat embedded on silicon-coated glass slides in Epon. VGLUT-positive tissues were obtained from frontal cortex area 1 (supplemental Fig. 1, available at www.jneurosci.org as supplemental material). Tissues were then serially resectioned to $70 \mathrm{~nm}$ thickness using a ultramicrotome. Cortical areas were delineated using standard cytoarchitectonic criteria (Paxinos and Watson, 1998). VGLUT1- and VGLUT2-positive terminals were selected randomly during observation under electron microscopy.

Frontal cortex is also called agranular cortex, which is described as being five layered, without a conventional granular layer IV (Donoghue and Wise, 1982). Although we cannot observe conventional cortical six-layered cytoarchitecture in motor cortex with light microscopic observation, optical dissector analysis reveals the existence of layer IV at the bottom of layer III (Skoglund et al., 1997). It corresponds with the middle VGLUT2-positive band. The VGLUT2positive fiber-rich band in agranular cortex was continuous with that

Table 1. Analysis of cortical spines for double innervation using VGLUT immunoreaction

\begin{tabular}{|c|c|c|c|c|c|c|c|c|c|c|}
\hline \multirow{3}{*}{ Layers } & \multicolumn{5}{|c|}{ VGLUT1-innervated spines } & \multicolumn{5}{|c|}{ VGLUT2-innervated spines } \\
\hline & \multirow{2}{*}{$\begin{array}{l}\text { Single } \\
\text { innervation }\end{array}$} & \multicolumn{3}{|c|}{ Double innervation with } & \multirow{2}{*}{ Total } & \multirow{2}{*}{$\begin{array}{l}\text { Single } \\
\text { innervation }\end{array}$} & \multicolumn{3}{|c|}{ Double innervation with } & \multirow{2}{*}{ Total } \\
\hline & & $\begin{array}{l}\text { Symmetrical } \\
\text { terminal }\end{array}$ & \multicolumn{2}{|c|}{ Asymmetrical terminal } & & & $\begin{array}{l}\text { Symmetrical } \\
\text { terminal }\end{array}$ & \multicolumn{2}{|c|}{ Asymmetrical terminal } & \\
\hline \multirow[t]{2}{*}{ । } & 79 & 1 & 1 & 2 & 83 & 77 & 15 & 0 & 0 & 92 \\
\hline & $95.2 \%$ & $1.2 \%$ & $1.2 \%$ & $2.4 \%$ & $100 \%$ & $83.7 \%$ & $16.3 \%$ & $0 \%$ & $0 \%$ & $100 \%$ \\
\hline$\|/\| \|$ & 63 & 0 & 2 & 0 & 65 & 59 & 10 & 0 & 0 & 69 \\
\hline IV & $92.1 \%$ & $2.6 \%$ & $5.3 \%$ & $0 \%$ & $100 \%$ & $90.4 \%$ & $8.7 \%$ & $0 \%$ & $1.0 \%$ & $100 \%$ \\
\hline \multirow[t]{2}{*}{ V } & 59 & 0 & 0 & 0 & 59 & 81 & $6^{b}$ & 0 & 1 & 88 \\
\hline & $100 \%$ & $0 \%$ & $0 \%$ & $0 \%$ & $100 \%$ & $92.0 \%$ & $6.8 \%$ & $0 \%$ & $1.1 \%$ & $100 \%$ \\
\hline \multirow[t]{2}{*}{ VI } & 39 & 0 & 0 & 0 & 39 & 65 & 3 & 0 & 0 & 68 \\
\hline & $100 \%$ & $0 \%$ & $0 \%$ & $0 \%$ & $100 \%$ & $95.6 \%$ & $4.4 \%$ & $0 \%$ & $0 \%$ & $100 \%$ \\
\hline Total & 280 & 2 & 5 & 2 & 289 & 376 & 43 & 0 & 2 & 421 \\
\hline
\end{tabular}

${ }^{a}$ One double-innervated spine head received two symmetrical inputs.

${ }^{b}$ One double-innervated spine received two symmetrical inputs on the head and neck. 


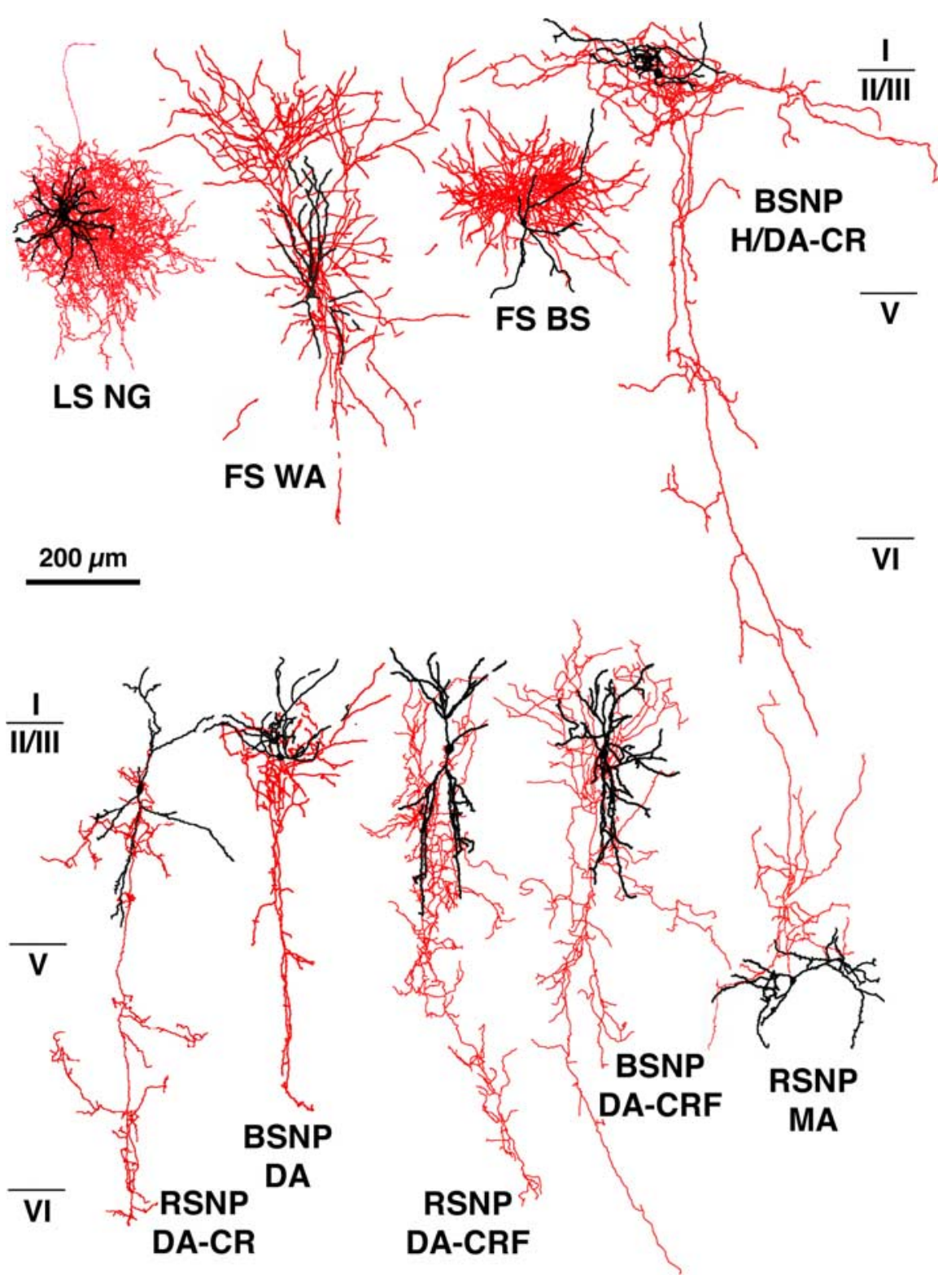

Figure 1. Cortical nonpyramidal cells used in this study. Nine nonpyramidal cells were studied for synaptic target structures using $3 \mathrm{D}$ reconstructions of successive EM sections. Red indicates axons, and black indicates soma and dendrites. WA, Wide arbor cell; BS, basket cell; MA, Martinotti cell; RSNP, regular spiking nonpyramidal.

in layer IV of the somatosensory cortex. Therefore, we could identify the middle VGLUT2-dense band as layer IV tentatively. This layer classification was also supported by the colocation of the layer IV marker retinoid orphan receptor $\beta$ (ROR $\beta$ ) (Schaeren-Wiemers et al., 1997) (our unpublished observation).

VGLUT-positive synapse volume density. Serial ultrathin sections of 70 $\mathrm{nm}$ thickness from VGLUT-positive tissue were imaged with electron microscopy $(15,000 \times)$, and synapses were counted using a stereological method. Sets of serial ultrathin sections for stereological analysis were randomly chosen from those synapses included in Table 1 . The area of images was $15.47 \mu \mathrm{m}^{2}(3.33 \times 4.65 \mu \mathrm{m})$. We counted 297 VGLUT1positive synapses in 47 sets of serial ultrathin sections (15.3 $\pm 3.4 ; 7-23$ successive sections; total volume was $955.4 \mu^{3}$ ) and 171 VGLUT2positive synapses in 50 sets $(16.4 \pm 3.8 ; 9-26$ successive sections; total volume was $964.9 \mathrm{\mu m}^{3}$ ) from layers I-VI. To estimate the relative volume density of cortical VGLUT1 and VGLUT2 recipient spines, the density from all layers were averaged.
Postembedding immunohistochemistry Electron microscopic observations and postembedding GABA immunohistochemistry. Two male Wistar rats (6 weeks, 140-160 g) were used in accordance with National Institute of Physiological Sciences Animal Care and Use Committee guidelines. Fixative was $4 \%$ paraformaldehyde containing $0.2 \%$ picric acid and $0.5 \%$ glutaraldehyde in PB. Sections were immunohistochemically stained with DAB using primary antiserum against VGLUT1 or VGLUT2. Sections were then flat embedded on silicon-coated glass slides in Epon. VGLUTpositive tissues were serially sectioned in $90 \mathrm{~nm}$ thickness. For GABA postembedding immunohistochemistry, ultrathin sections on nickel mesh grids (\#200) were washed with TBS containing $0.1 \% \mathrm{TX}$ and incubated with rabbit antiserum for GABA (1:5000, A-2052; Sigma, St. Louis, MO) in TBS containing $0.1 \%$ TX overnight at RT, followed by colloidal gold $15 \mathrm{~nm}$ conjugated anti-rabbit $\operatorname{IgG}(1: 100$, catalog \#GAR15; BBInternational, Cardiff, UK) overnight at RT in TBS containing $0.1 \%$ TX and final staining with $1 \%$ uranyl acetate, followed by lead citrate.

Postembedding $G A B A_{A} \alpha 1$ subunit immunohistochemistry with tissue embedded in Lowicryl postembedding immunohistochemistry. Freeze substitution and low-temperature embedding in Lowicryl resin was performed as described previously (Wu et al., 2005). Briefly, slices of frontal cortex of adult rat brains fixed with $4 \%$ paraformaldehyde, $0.05 \%$ glutaraldehyde, and $0.2 \%$ picric acid in $0.1 \mathrm{M} \mathrm{PB}$ were frozen by plunging into liquid propane $\left(-185^{\circ} \mathrm{C}\right)$ in a cryofixation unit (EM CPC; Leica, Wein, Austria). Freeze substitution and low-temperature embedding in Lowicryl HM20 were performed. Ultrathin sections $(90 \mathrm{~nm})$ were stained with a homemade antiserum against $\mathrm{GABA}_{\mathrm{A}}$ receptor $\alpha 1$ subunit 29-57 (1:1000) (supplemental Fig. 2 , available at www.jneurosci.org as supplemental material) using $15 \mathrm{~nm}$ colloidal goldconjugated secondary antiserum (1:50, catalog \#GAR15; BBInternational). We also performed double-postembedding immunohistochemistry with combined antiserums against $\mathrm{GABA}_{\mathrm{A}}$ receptor $\beta 2 / 3$ subunit (1:250; mouse, bd17; generous gift from Dr. J.-M. Fritschy, University of Zurich, Zurich, Switzerland) using a 15 $\mathrm{nm}$ colloidal gold-conjugated secondary antiserum (1:50; catalog \#GAM15; BBInternational) and against AMPA receptor GluR2/3 subunits (1:100, rabbit, catalog \#AB1506; Chemicon, Temecula, CA) using a $10 \mathrm{~nm}$ colloidal gold-conjugated secondary antiserum (1:30, catalog \#GAR10; BBInternational).

Three-dimensional reconstruction of successive ultrathin sections Slice recording cells. Slices containing stained neurons were cut into serial ultrathin sections (90 nm thickness) and mounted on Formvar-coated single-slot grids (NOTCH-NUM grids, $1 \times 2 \mathrm{~mm}$ slot, SynapTek; Pelco, Redding, CA) with Formvar membrane. Electron microscopic images of the labeled terminals and associated structures were captured using a CCD camera (Megaplus 1.4i; Eastman Kodak, Rochester, NY) and reconstructed using a 3D reconstruction system with the software developed by Noesis as an extension of their Visilog program.

VGLUTs-positive boutons. Serial ultrathin sections of VGLUT-positive tissue were mounted on Formvar-coated single-slot grids, the labeled terminals and associated structures were photographed, and image files were made 
from EM films with scanner (GT-9800F; Epson, Suwa, Japan). The structures were reconstructed using a $3 \mathrm{D}$ reconstruction system with the software Reconstruct (http://www.synapses.bu.edu/tools/index.htm).

\section{Statistics}

We used Mann-Whitney $U$ test for statistical analysis to compare the spine head volume and area of synaptic junction area between spines innervated by VGLUT1 and VGLUT2 afferents and $\chi^{2}$ test to compare the proportion of perforated synapses between cortical spines innervated by VGLUT1- and VGLUT2-positive terminals.

\section{Results}

\section{Target structure of cortical nonpyramidal cells}

We recorded 591 nonpyramidal cells filled biocytin using in vitro slice preparation. The morphologies of 526 neurons (89\%) were recovered after fixation and immunohistochemical processing. Many of the reconstructed cells were used for morphological analysis previously (Karube et al., 2004; Kawaguchi et al., 2006). Nine interneurons with morphologies and axonal arborizations typical of different subtypes of nonpyramidal cells (Fig. 1) were selected based on our previous analysis (Karube et al., 2004; Kawaguchi et al., 2006) and resectioned into ultrathin (90 nm) sections for $3 \mathrm{D}$ reconstruction of axonal boutons and their postsynaptic structures, including spines. Reconstructed neurons included two fast-spiking (FS) cells, a late-spiking (LS) cell, a Martinotti cell, a horizontal and descending arbor (H/DA) cell, and four intracolumner descending axon cells (DA) (also called double-bouquet cells) expressing either calretinin (CR) $(n=2)$ or corticotrophin-releasing factor (CRF) $(n=2)$ (Fig. 1), which are nonoverlapping subpopulations of H/DA and DA cells (Karube et al., 2004). We classified the target structure as dendritic shaft on the basis of existence of microtubule and/or mitochondria (Fig. $2 B, C$ ) and cylindrical shape of its $3 \mathrm{D}$ reconstructed image and as spine on the basis of lack of those structures and spine shape of its 3D image. In all cells, we analyzed axon terminals in layers II/III and IV but not in layer I. In H/DA and DA cells, we also analyzed their descending axonal arborizations in layers V and VI. Because there were no distinct differences in target selection between the superficial layers (layers II/III and IV) and deeper layers (layers V and VI) (supplemental Fig. 3, available at www.jneurosci.org as supplemental material), we combined all data obtained from layers II/III through VI. Whereas only six neurons had synaptic boutons innervating postsynaptic somata [including the LS neurogliaform (NG) cell, FS cells, calretinin-positive H/DA and DA cells, and a burst spiking nonpyramidal (BSNP) DA cell] (Figs. 2A, 3A, 4), all cells made synaptic junctions onto dendritic shafts (Figs. $2 B, 3 B, 4$ ) and spines (Fig. $2 C, 3 C, 4$ ). Surprisingly, spines made up $33.4 \pm$ $9.3 \%$ (range of $25-50 \%$ ) of all synaptic targets, and $75.4 \pm 11.7 \%$ (range of 55-91\%) of targeted spines were also innervated by an asymmetrical excitatory synapse (Fig. 4). These results indicate that spines comprise a major postsynaptic target for cortical nonpyramidal cells in the rat cortex. We could not find an asymmetrical synaptic innervation on approximately one-quarter of the targeted spines. We think, however, that missing another synapse on the same spine may be mostly caused by parallel orientation of the junction area and sectioning direction (Karube et al., 2004). This oversight attributable to the angle effect would occur more frequently in the case of smaller objects. Most spines targeted by the nonpyramidal cells probably receive an asymmetrical synapse.

\section{The source of afferent excitatory input to spines}

We next investigated the source of afferent excitatory input onto spines coinnervated by GABAergic interneurons. Fixed sections

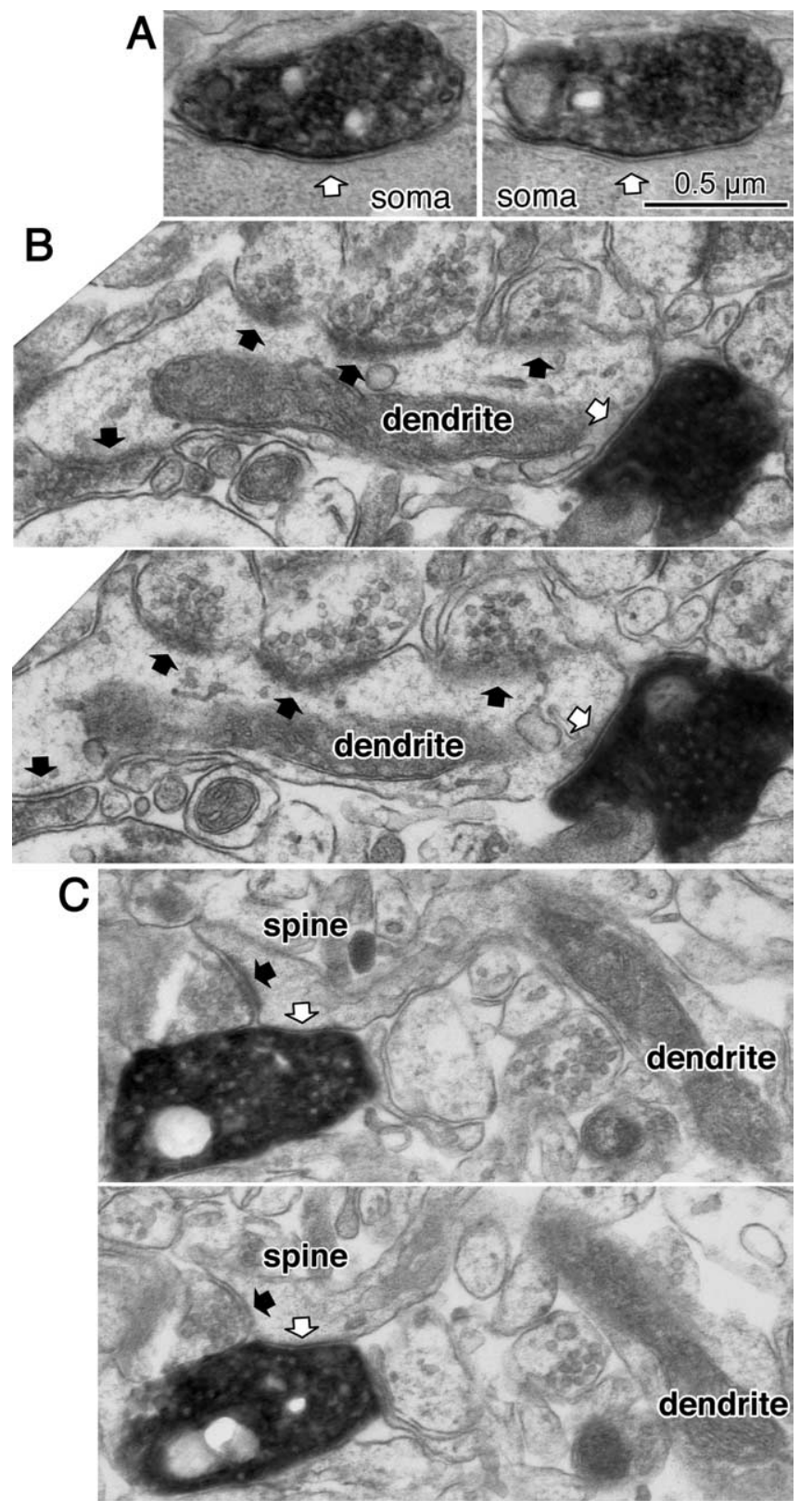

Figure 2. Synaptic target structures for cortical nonpyramidal cells. $A$, Successive ultrathin sections showing a symmetrical synapse (white arrow) of the LS NG cell onto a postsynaptic soma. $\boldsymbol{B}$, Successive ultrathin sections showing a symmetrical synapse (white arrow) from an RSNP DA-CRF cell onto a dendritic shaft with frequent asymmetrical inputs (black arrows). $C$ Successive ultrathin sections showing a symmetrical synapse (white arrow) from a BSNP DA-CR cell onto a spine head, which is also innervated by an asymmetrical synapse (black arrow). Scale bar in $\boldsymbol{A}$ also applies to $\boldsymbol{B}$ and $\boldsymbol{C}$.

of the frontal cortex of young adult rats were immunohistochemically stained with VGLUT1 or VGLUT2 antiserums (Fujiyama et al., 2001). These two isoforms of the glutamate vesicular transporter are useful because thalamocortical fibers exclusively express the VGLUT2 isoform, whereas cortical neurons (and hence corticocortical fibers) generally express VGLUT1 or only a limited number for both VGLUT1 and VGLUT2 (De Gois et al., 2005). As expected, fibers immunoreactive for VGLUT1 and VGLUT2 were differentially distributed throughout the cortical layers. Whereas VGLUT1-positive fibers were distributed throughout all cortical layers, VGLUT2-positive fibers were localized densely in the upper parts of layer I, in layer IV, and in the 


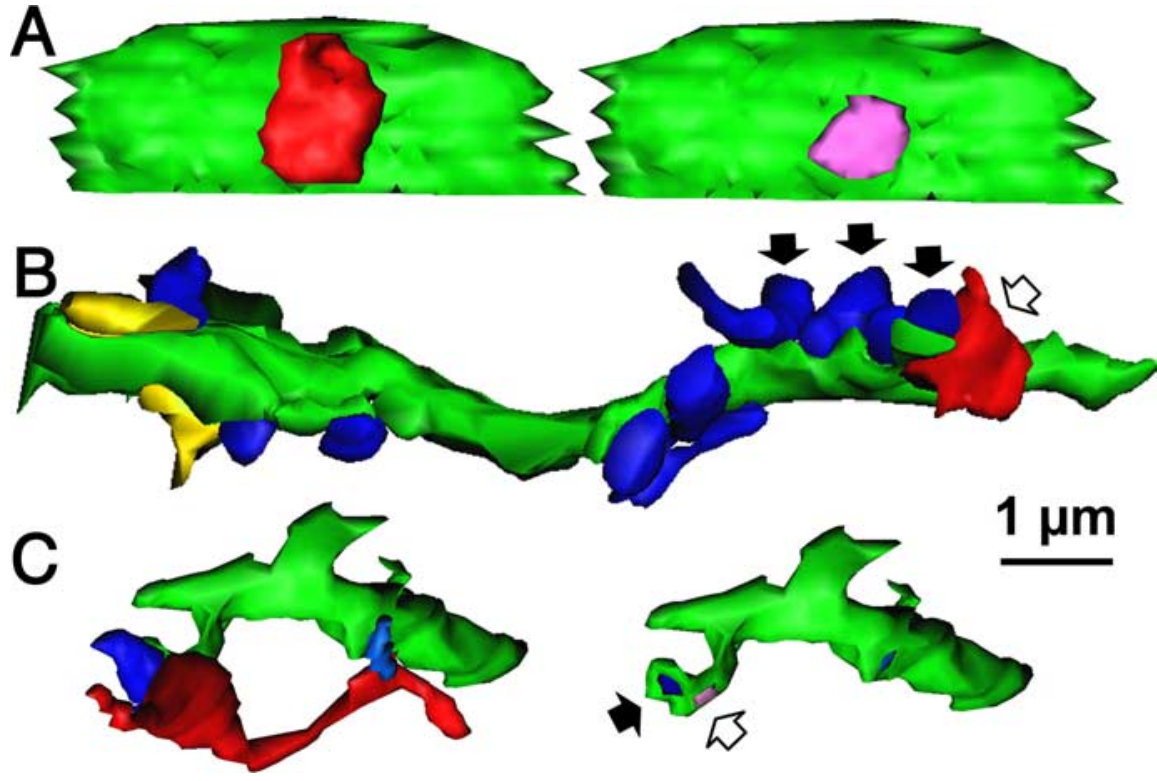

Figure 3. 3D reconstructed image of the synaptic structure of cortical nonpyramidal cells. $A, 3 \mathrm{D}$ reconstructed image of the synaptic structure shown in Figure $2 A$. The axonal terminal of the $L S N G$ cell (red) innervates the soma (green). Right image shows $3 \mathrm{D}$ image of targeted soma after removing the bouton. The synaptic junction is shown (pink). $\boldsymbol{B}, 3 \mathrm{D}$ reconstructed image of synaptic structure shown in Figure $2 B$. Arrows indicate the same axon terminal boutons shown in Figure $2 B$. Note that no spines are observed in the target dendrite (green). Red is an axon terminal of RSNP DA-CRF cell. Blue structures are boutons forming asymmetrical synapses. Yellow structures are boutons forming symmetrical synapses. C, 3D reconstructed image of synaptic structure shown in Figure 2C. An axon terminal of BSNP DA-CR cell (red) innervates the spine head (green), which is also innervated by an asymmetrical synaptic terminal (blue). Right image without boutons shows two synaptic junctions (pink and dark blue). Scale bar in $\boldsymbol{A}$ also applies to $\boldsymbol{B}$ and $\boldsymbol{C}$.

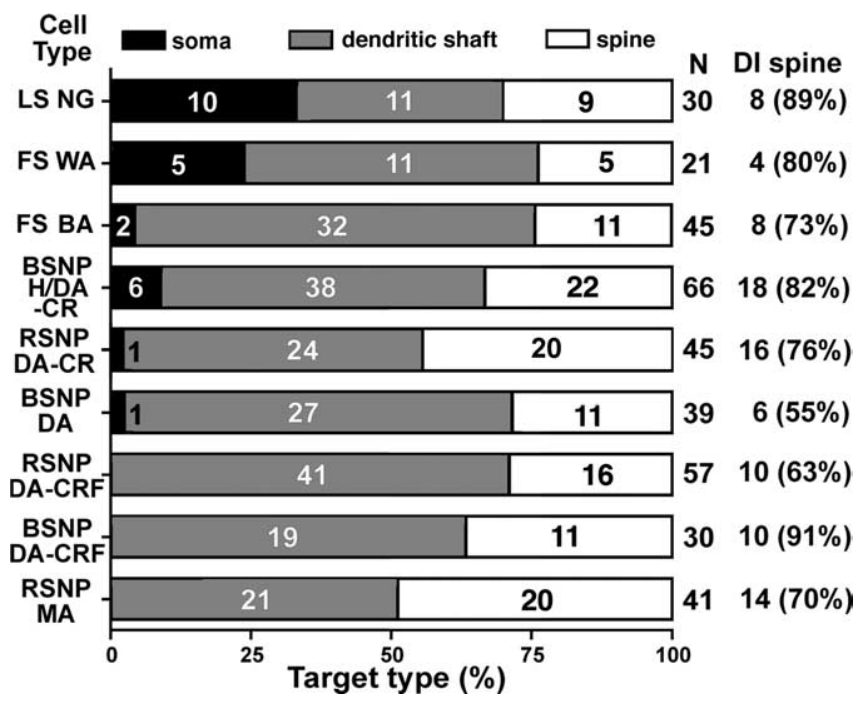

Figure 4. Summary of target structures of nonpyramidal cell boutons. All types of nonpyramidal cells targeted spine heads, most of which were double-innervated (DI) spines. MA, Martinotti cell.

lower half of layer V (Fig. 5). The VGLUT2-immunoreactive pattern in layer IV reflects the known distribution of thalamocortical fibers (Groenewegen, 1988; Berendse and Groenewegen, 1991; Agmon et al., 1993; Jones, 1998), and intense VGLUT2 staining was observable in layer IV of the somatosensory barrel cortex (Fig. 5B) in which VGLUT2-positive fibers shared an identical distribution pattern with the layer IV marker $\operatorname{ROR} \beta$ (SchaerenWiemers et al., 1997), and the similar colocalization was also found in frontal cortex (our unpublished observation). A com- bined study using in situ hybridization of VGLUT2 mRNA and retrograde tracer found that $90 \%$ of VGLUT2 input to prefrontal cortex arises from thalamus, whereas the remaining $10 \%$ comes from other areas such as claustrum and hypothalamus (Hur and Záborszky, 2005). The distribution patterns of excitatory boutons suggest that most VGLUT2immunoreactive fibers originate from thalamocortical neurons (Fujiyama et al., 2001; Hur and Záborszky, 2005). The vast majority of VGLUT1-positive terminals in the neocortex likely arise from cortical pyramidal neurons, all of which express VGLUT1 mRNA (Fremeau et al., 2001). This conclusion is further supported by data showing that lesions of the specific thalamic nuclei (which provide excitatory input to the cortex) do not lower cortical VGLUT1 immunoreactivity (Fujiyama et al., 2001). To our knowledge, all intracortical afferent terminals express VGLUT1, either alone or, in a minority of terminals, along with VGLUT2. Therefore, all VGLUT1-expressing terminals in our present study are assumed to be intracortical synapses.

To identify the source of excitatory input to spines innervated by both excitatory and inhibitory synapses, we used electron microscopy to analyze successive ultrathin sections stained for either VGLUT1 or VGLUT2. We analyzed randomly selected spine heads innervated by VGLUT1- or VGLUT2-positive axon terminals in successive ultrathin sections (Figs. 6, 7). In total, we selected 705 spine heads distributed in all cortical layers (Table 1). Spines were innervated by excitatory boutons expressing VGLUT1 $(n=284)$ (Fig. $6,8 B)$ or VGLUT2 $(n=421)$ (Figs. 7 , $8 A$ ). Because VGLUT1- and VGLUT2-innervated spine heads were selected for comparison, the relative number of selected VGLUT1- and VGLUT2-positive terminals do not reflect the relative density of these excitatory afferents.

Although only a small population of spine heads was double innervated by a symmetrical, presumably GABAergic, terminal, excitatory inputs to these spines were almost exclusively VGLUT2-positive, indicating a thalamocortical origin (Table 1). Forty-three of the 421 spine heads innervated by VGLUT2positive synapses $(10.2 \%)$ also received a symmetrical synaptic input. Interestingly, a higher proportion of double-innervated spines were found in the superficial layers than were observed in deeper layers (Table 1), which may indicate that they are innervated by nonspecific thalamocortical connections (Jones, 1998). In most cases, double-innervated spines were contacted by a single symmetrical synapse, but double innervation by two symmetrical inputs was observed in two spines (Fig. $8 A, F$ ). Only rarely (including 7 of 284 spines innervated by VGLUT1-positive terminals and 2 of 421 spines innervated by VGLUT2-positive terminals) were two excitatory synapses found on the same spine head (Table 1). The vast majority of spine heads innervated by VGLUT1-positive terminals had no other synaptic input $(96.8 \%)$ (Fig. 6, 8B,G; Table 1), and double innervation of VGLUT1receptive spines was only observed in 9 of 284 cases: five were contacted by a second VGLUT1-positive synapse (1.8\%), two 
received a second VGLUT1-negative asymmetrical synapse $(0.7 \%)$, and two others were innervated by a symmetrical synapse $(0.7 \%)$ (Table 1$)$.

We also measured the density of VGLUT1- and VGLUT2-positive synapses in frontal cortex using a stereological method using most of the sample from layers I-VI used for Table 1. We combined all data of VGLUT1 or VGLUT2 to obtain overall proportion of recipient spines of VGLUT1- and VGLUT2-positive axon terminals. The volume density was $0.311 /$ $\mu \mathrm{m}^{3}$ for VGLUT1 synapses (297 synapses/ $\left.955.429 \mu \mathrm{m}^{3}\right)$ and $0.172 / \mu \mathrm{m}^{3}$ for VGLUT2 synapses (166 synapses/964.925 $\mu \mathrm{m}^{3}$ ). VGLUT1-positive synapses were found to be almost double the volume density of VGLUT2 synapses. Dendritic synapses were very rare compared with spinous synapses. Of all synapses, we found only 29 (9.8\%) synapse onto dendritic shafts for VGLUT1-positive bouton and only five (2.9\%) synapses for VGLUT2 bouton.

\section{GABAergic nature of symmetrical} synaptic terminals on the spine

We next confirmed that symmetrical synapses on spines comprise GABAergic terminals. Successive ultrathin sections (90 nm) of VGLUT2-immunostained cortex from young adult rats were labeled for GABA by postembedding immunohistochemistry using $15 \mathrm{~nm}$ colloidal gold-conjugated secondary antiserum (Kawaguchi and Kubota, 1998). The densities of colloidal gold particles were clearly different between GABA-positive (88.6 \pm 64.2 particles $\left./ \mu \mathrm{m}^{2} ; n=35\right)$ and GABA-negative (0.4 \pm 1.1 particles $\left./ \mu \mathrm{m}^{2} ; n=66\right)$ boutons. We examined 33 doubleinnervated spine heads, and, in all cases, the secondary nonVGLUT2-positive input was a GABA-positive synaptic bouton that was associated with a symmetrical synaptic junction (Fig. $8 C$ ). Two spine heads of 33 were innervated by two GABApositive synaptic terminals. We found no spine heads in which VGLUT2-positive asymmetrical terminals were found with GABA-negative symmetrical synaptic boutons. These data suggest that symmetrical synaptic junctions onto spines receiving thalamocortical (VGLUT2-positive) excitatory input are GABAergic.

We next confirmed that $\mathrm{GABA}_{\mathrm{A}}$ receptors are localized to symmetrical synaptic junctions in double-innervated spines. Freeze substitution and low-temperature embedding in Lowicryl resin was used in ultrathin sections $(90 \mathrm{~nm})$ that were labeled for an antiserum against the $\mathrm{GABA}_{\mathrm{A}}$ receptor $\alpha 1$ subunit 29-57 (supplemental Fig. 2, available at www.jneurosci.org as supplemental material) using a $15 \mathrm{~nm}$ colloidal gold-conjugated secondary antiserum. We identified gold-particle labeling of the synaptic junctions of symmetrical synapses onto spines (Nusser et al., 1996) (mean of $2.95 \pm 1.16$ particles per $100 \mathrm{~nm}$ of postsynaptic density; $n=16$ ) (Fig. $8 D$ ). We also performed doublepostembedding immunohistochemistry with antiserums against the $\mathrm{GABA}_{\mathrm{A}}$ receptor $\beta 2 / 3$ subunits (using a $15 \mathrm{~nm}$ colloidal goldconjugated secondary antiserum) and against the AMPA receptor GluR2/3 subunits (using a $10 \mathrm{~nm}$ colloidal gold-conjugated secondary antiserum). We identified gold-particle double label- ing of synaptic junctions onto double-innervated spines (mean count was $2.65 \pm 0.65$ particles per $100 \mathrm{~nm}$ postsynaptic density for $\mathrm{GABA}_{\mathrm{A}}$ receptor $\beta 2 / 3$ subunits and $4.24 \pm 1.67$ particles per $100 \mathrm{~nm}$ postsynaptic density for AMPA receptor GluR2/3 subunits; $n=7$ ) (Fig. $8 E$ ). These data suggest that symmetrical synapses onto spines form functional inhibitory synapses expressing $\mathrm{GABA}_{\mathrm{A}}$ receptors containing $\alpha 1$ subunits and/or $\beta 2 / 3$ subunits, whereas associated asymmetrical synapses express AMPA receptors.

Comparison of the head volume and junctional area between spines innervated by VGLUT1- and VGLUT2-positive boutons VGLUT2-positive fibers in the cortex are almost exclusively of thalamic origin (Fujiyama et al., 2001; Hur and Záborszky, 2005). Although a few VGLUT2-positive neurons are found in the cortex, they usually coexpress VGLUT1 as well (De Gois et al., 2005). Our data show that asymmetrical inputs onto double-innervated spine heads are almost exclusively VGLUT2-positive axon terminals and that VGLUT1-positive terminals almost never share postsynaptic spines with other synapses. Therefore, the vast majority of double-innervated spines likely receive thalamocortical inputs.

Because spine size is related to synaptic efficacy and plasticity (Takumi et al., 1999; Matsuzaki et al., 2001, 2004; Okamoto et al., 2004; Zhou et al., 2004), we compared physical characteristics of VGLUT1- and VGLUT2-innervated spine. First, we compared the head volume between spines innervated by VGLUT1- and VGLUT2-positive boutons and found that spine heads associated with VGLUT2-positive terminals were significantly larger than those associated with VGLUT1-positive inputs $(p<0.001)$ (Fig. $8 A, B, F, G, 9 A$; Table 2 ). We also compared the area of synaptic junctions formed by VGLUT1- and VGLUT2-positive boutons and found that synaptic junctions associated with VGLUT2 terminals were significantly larger than those associated with VGLUT1-positive inputs $(p<0.0001)$ (Figs. $8 A, B, F, G, 9 B$; Table 2). Because there was no significant difference in the volume 

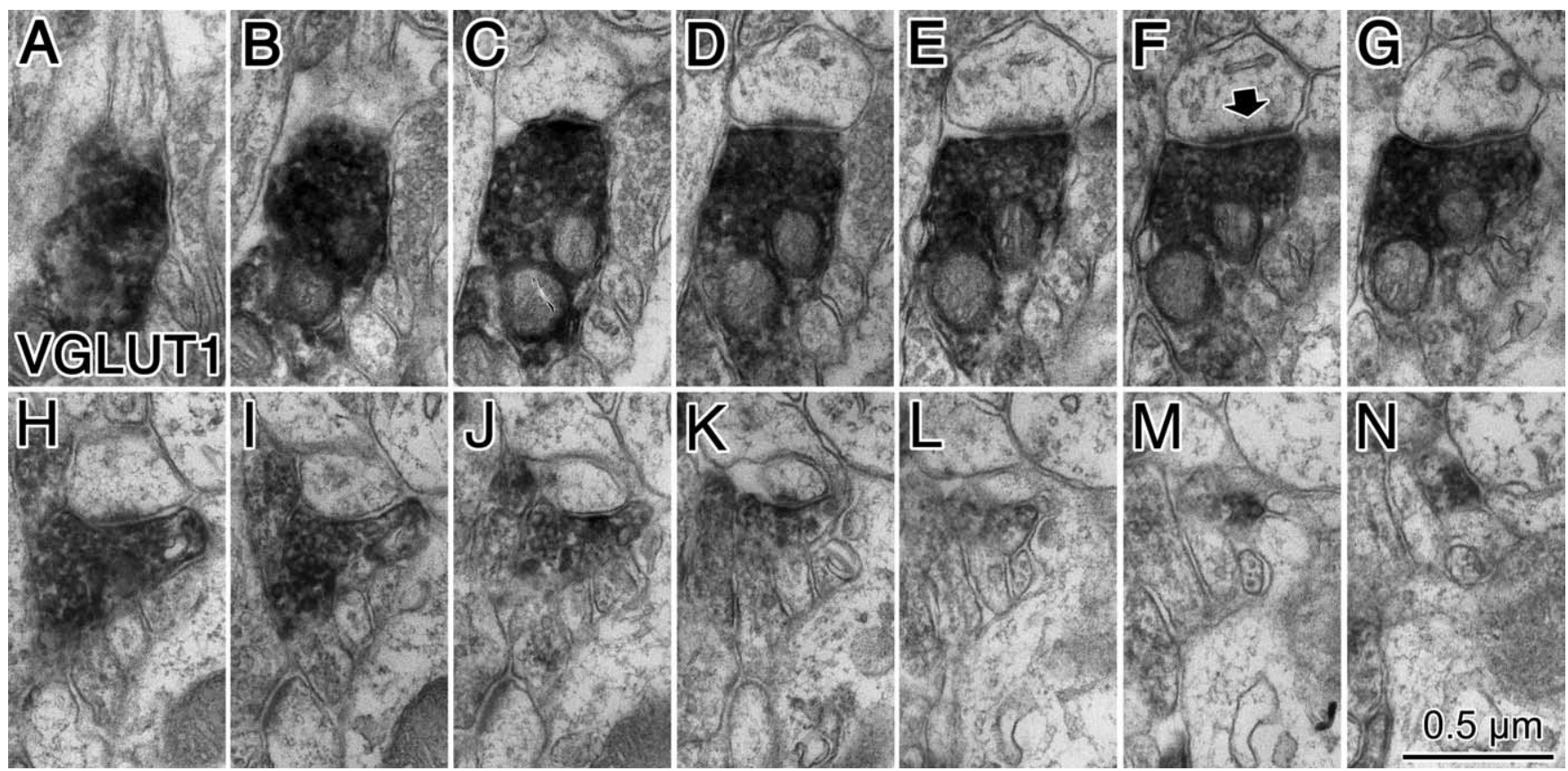

Figure 6. Cortical spine innervated by a VGLUT1-positive terminal. A-N, Successive ultrathin sections of an entire spine head that was innervated by a VGLUT1-positive axon terminal. A single asymmetrical synapse was observed (arrow in $\boldsymbol{F}$ ).
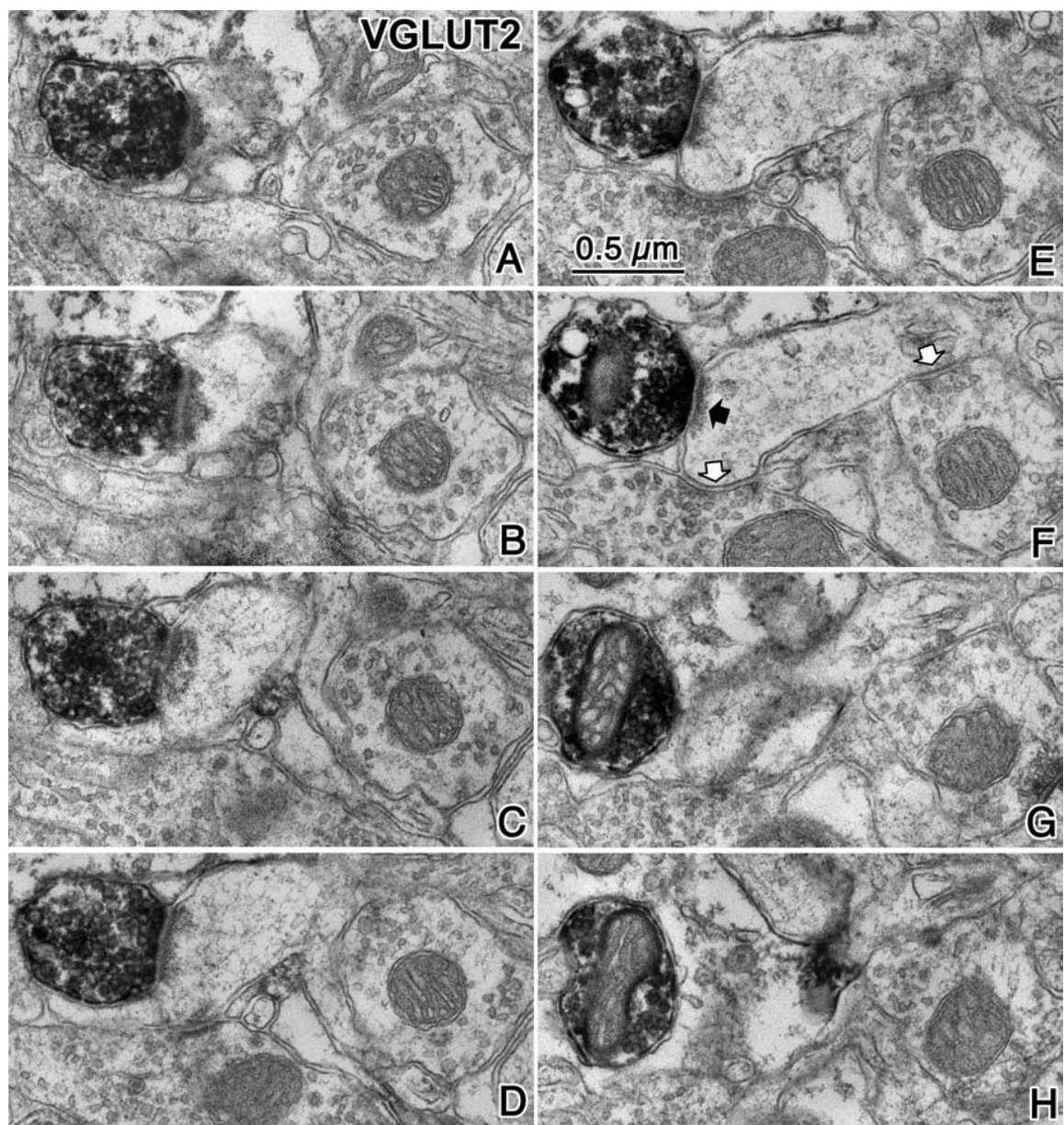

Figure 7. Cortical spine innervated by a VGLUT2-positive terminal. $\boldsymbol{A}-\boldsymbol{H}$, Successive ultrathin sections of a spine head innervated by a VGLUT2-positive axon terminal (black arrow in $\boldsymbol{F}$ ). Two additional symmetrical synapses contacted this spine head (white arrows in $\boldsymbol{F}$ ). of single- and double-innervated VGLUT1-receptive or VGLUT2-receptive spine heads (Fig. 9A; Table 2), the increased volume of VGLUT2-receptive spines cannot be explained simply by their greater tendency for double innervation. Likewise, we also found no significant difference in the area of synaptic junctions when comparing VGLUT1-positive synapses onto single- and double-innervated spines or VGLUT2-positive inputs onto single- or double-innervated spines (Fig. 9B; Table 2).

During the process of $3 \mathrm{D}$ reconstruction, we observed many perforated synapses associated with VGLUT1- and VGLUT2-positive terminals. A recent study demonstrated that perforated synapses have enlarged synaptic areas and more AMPA receptor expression than nonperforated synapses in CA1 pyramidal neurons of the hippocampus, suggesting that perforated synapses provide stronger synaptic drive to postsynaptic neurons (Nicholson et al., 2006). When we compared spines with perforated and nonperforated synapses, we observed four morphologically distinct synaptic shapes among presynaptic boutons: nonperforated, perforated, U-shaped, and twinjunctional synapses (Fig. 9C; Table 3). We also checked whether symmetrical synapses contacted with double-innervated spines were perforated and did not find any of those $(n=46)$. All symmetrical synapses were nonperforated synapses. 

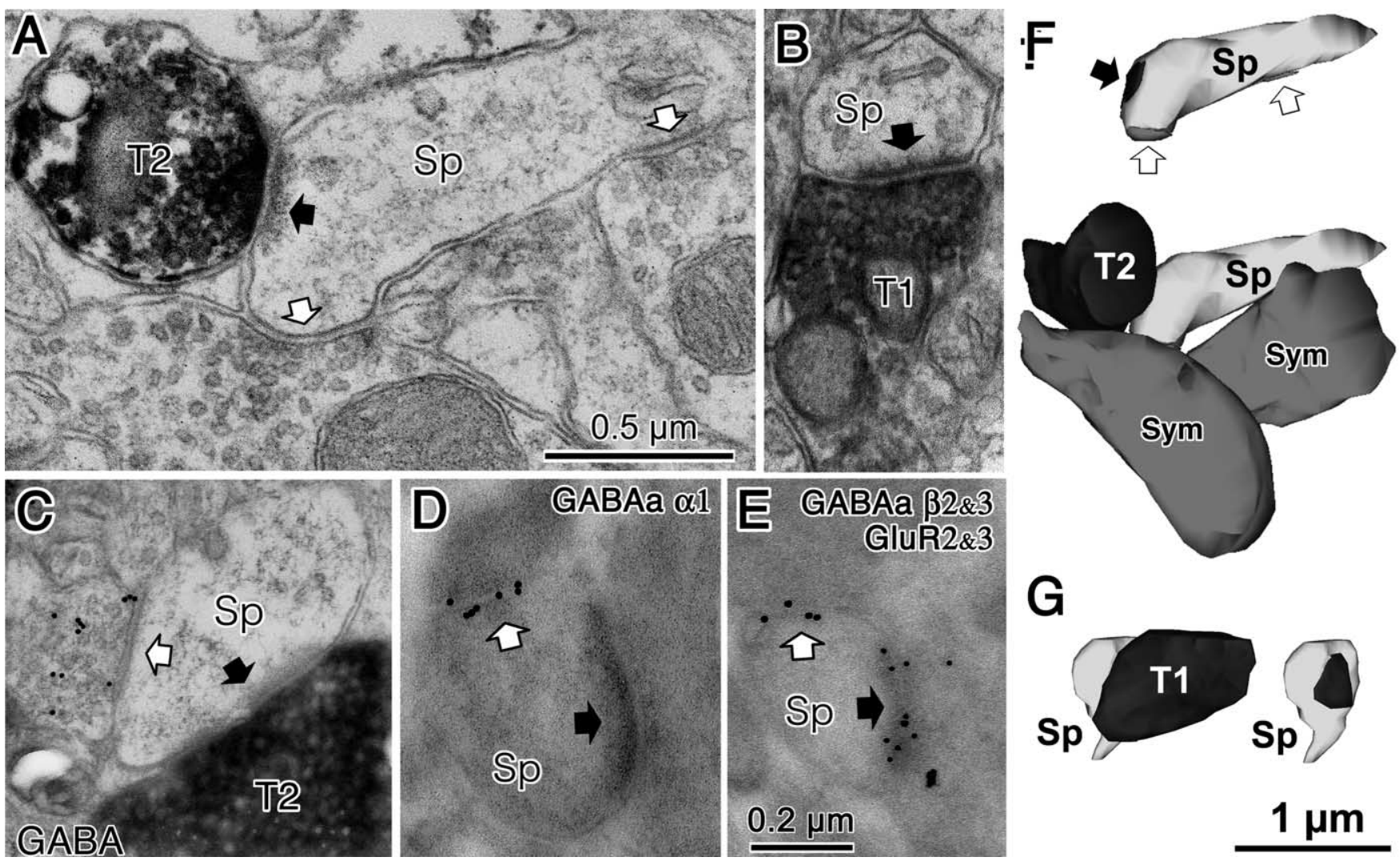

G

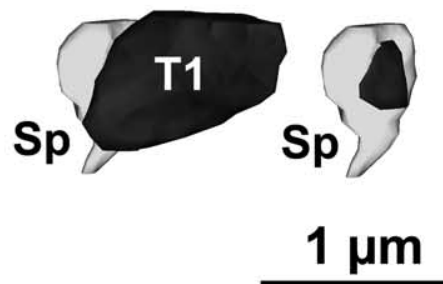

Figure 8. Synaptic innervations of cortical spines. $A$, A cortical spine ( $S p$ ) was coinnervated by a VGLUT2-positive (T2) asymmetrical synapse (black arrow) and two symmetrical synaptic terminals (white arrows) and was shown in Figure 7F. B, A cortical spine (Sp) was innervated by a VGLUT1-positive (T1) asymmetrical synapse (black arrow) and was shown in Figure 6F. C, A spine head (Sp) was innervated by both a VGLUT2-positive (T2) asymmetrical synapse (black arrow) and a GABA-positive (gold particle labeled) symmetrical synaptic terminal (white arrow). D, A spine head (Sp) innervated by an asymmetrical synapse (black arrow) was also innervated by a symmetrical synaptic terminal (white arrow). Gold particles label $\mathrm{GABA}_{\mathrm{A}} \alpha 1$ subunits localized along the synaptic junction of the symmetrical synapse. E, A spine head (Sp) innervated by an asymmetrical synapse (black arrow) was also innervated by a symmetrical synaptic terminal (white arrow). Larger gold particles $\left(15 \mathrm{~nm}\right.$ ) labeled $G A B A_{A} \beta 2 / 3$ subunits localized along the synaptic junction of the symmetrical synapse and smaller particle (10nm) labeled glutamate receptor GluR2/3 subunits of the associated asymmetrical synaptic junction. Scale bars: $\boldsymbol{A}$ applies to $\boldsymbol{B}$ and $\boldsymbol{C} ; \boldsymbol{E}$ applies to $\boldsymbol{D}$. $\boldsymbol{F}, 3 \mathrm{D}$ reconstructed image of the spine and presynaptic terminals shown in $\boldsymbol{A}$. Bottom image is the VGLUT2-positive bouton (T2, black) contacting the spine head (Sp, light gray) with a synaptic junction. This spine is also innervated by two symmetrical inputs (Sym, dark gray). Top image shows synaptic junctions (black arrow for VGLUT2 synapse and white arrows for symmetrical synapses) on the spine head. $\boldsymbol{G}, 3 \mathrm{D}$ reconstructed image of the spine and presynaptic terminal shown in $\boldsymbol{B}$. The VGLUT1-positive bouton (T1, black) contacts the spine head (SP, light gray) with a synaptic junction. Left image is with the VGLUT1 bouton (black), and right image shows the synaptic junction only (black).

We analyzed spines with perforated, U-shape, and twinjunctional asymmetrical synapses together as "perforated synapses" because they appear quite similar under EM observation and may simply reflect variable morphologies of mature synaptic contacts. In serial ultrathin sections, perforated synapses were identified when there were two or more splits in the synaptic junction (Fig. 10). The ratio of perforated to nonperforated synapses in VGLUT2-positive terminals was significantly greater than that in VGLUT1-positive terminals $\left(p<0.001, \chi^{2}\right.$ test $)$, indicating that more than half $(54.4 \%)$ of thalamocortical inputs (VGLUT2-positive) make perforated synapses onto spines, whereas only one-quarter $(22.4 \%)$ of corticocortical inputs (VGLUT1-positive) make perforated synapses. When we compared the volume of spine heads innervated by perforated and nonperforated VGLUT1- and VGLUT2-positive terminals, we found that spines receiving perforated inputs were significantly larger than spines receiving nonperforated inputs (VGLUT1, $p<$ 0.0001; VGLUT2, $p<0.01$ ) (Figs. 9A, $C$, 10; Table 2). Furthermore, we found that the area of synaptic junctions made by perforated VGLUT1- or VGLUT2-positive terminals were larger than that by nonperforated junctions of similar presynaptic origin $(p<0.0001)$ (Fig. 9B,C; Table 2). These data demonstrate that, regardless of afferent input type (VGLUT1 or VGLUT2), spines and synaptic junctions are larger when receiving input from perforated rather than nonperforated synapses.

\section{Discussion}

Our data demonstrate that cortical interneurons of all subtypes provide robust input to the dendritic shafts and spines of other cortical neurons (Fig. 11). Furthermore, GABA-positive synapses onto spines are associated with postsynaptic $\mathrm{GABA}_{\mathrm{A}}$ receptor expression and are targeted specifically to spines that also receive excitatory thalamocortical input. Because inhibition by $\mathrm{GABA}_{\mathrm{A}}$ receptors may generate shunting inhibition, inhibitory inputs onto electrically compact spines may permit interneurons to preferentially gate thalamocortical afferent input to the cortex but allow, or even facilitate, synaptic integration of excitatory inputs at other dendritic locations (Gulledge and Stuart, 2003).

Pyramidal neurons, which comprise the majority $(\sim 80 \%$, $1: 0.25$ is the pyramidal cell/nonpyramidal cell ratio) of neocortical neurons (Beaulieu et al., 1992), are the source of the vast majority of spines in the neocortex and have a much greater total dendritic length than nonpyramidal neurons $[\sim 10$ vs $3 \mathrm{~mm}$, respectively (Karube et al., 2004; Morishima and Kawaguchi, 2006)]. Because only a minority of nonpyramidal neurons [ 25\%, including Martinotti cells (Kubota et al., 1994)] have 


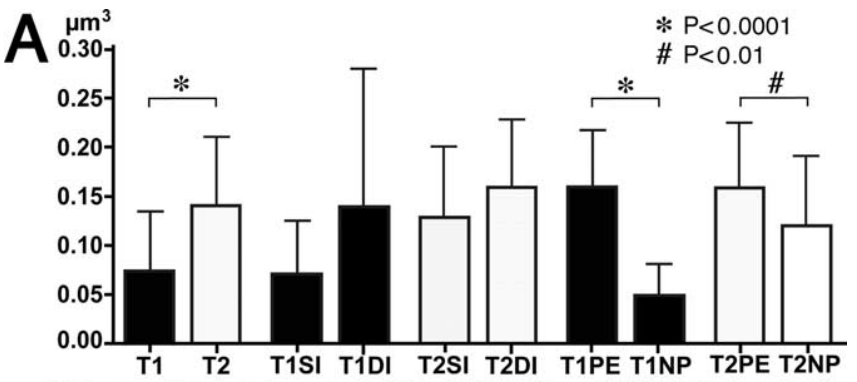

Volume of spine innervated by VGLUT1- or VGLUT2- terminals

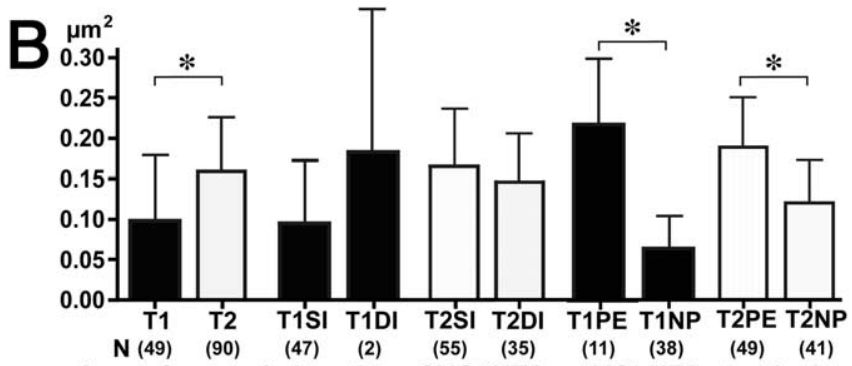

Area of synaptic junction of VGLUT1- or VGLUT2- terminals
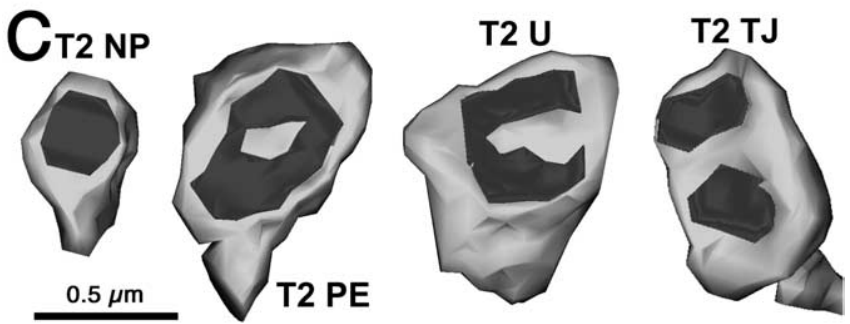

Figure 9. $\quad \boldsymbol{A}, \boldsymbol{B}$, Summary of spine head volume $(\boldsymbol{A})$ and synaptic junction area $(\boldsymbol{B})$ of VGLUT1and VGLUT2-innervated spines. Mean and SD of volume of different spines types innervated by VGLUT1 and VGLUT2. * $p<0.0001$; $p<0.01$. T1, VGLUT1; T2, VGLUT2; SI, single-innervated spine; DI, double-innervated spine; PE, spine innervated by perforated synapse; NP, spine innervated by nonperforated synapse. $C$, 3D reconstructed images of VGLUT2-innervated spines. Spines with nonperforated (NP), perforated (PE), U-shape (U), or twin-junctional (TJ) synapse.

high spine densities on their dendrites [which is only $\sim 25 \%$ of the density found on typical pyramidal neurons (Kawaguchi et al., 2006)], we can estimate the ratio of spine heads that originate from nonpyramidal cells in cortex by multiplying these proportions: $0.25 \times 0.3 \times 0.25 \times 0.25$, giving the total relative proportion of nonpyramidal spines as 0.00469 . Therefore, $<0.5 \%$ of all spines in the cortex belong to nonpyramidal cells, whereas $>99.5 \%$ of spines are on pyramidal neurons. Our data show that double-innervated spines make up $\sim 10 \%$ of all VGLUT2innervated spines in cortex. Because the density of VGLUT2positive synapses is approximately half of the density of VGLUT1-positive synapses, VGLUT2-positive synapses comprise approximately one-third of all cortical excitatory terminals.
We can therefore calculate the proportion of double-innervated spines to be $\sim 3 \%$ of all cortical excitatory synapses. Furthermore, we can assume that most, if not all, double-innervated spines are associated with pyramidal cells because nonpyramidal neuron spines comprise a much smaller population $(<0.5 \%$ of all spines $)$ than the population of double-innervated spines. Indeed, double-innervated spines have been reported previously to occur in pyramidal cell dendrites (Porter and White, 1986). Additional investigation will be required to determine whether doubleinnervated spines occur preferentially in different cellular compartments (basal vs apical dendrites, tufts, etc.).

There are some discrepancies between our data regarding the proportion of GABAergic terminals targeting spines (33.4\%) and previous results from monkey visual cortex estimating that $\sim 25 \%$ of GABAergic targets are spines (Beaulieu et al., 1992). This discrepancy may reflect variability among species or cortical areas. Alternatively, the difference may be attributable to differences in the targets of subtypes of GABAergic neuron. Although the nine neurons used in this study contain mostly the nonpyramidal cell subtype, some of minor ones were not included. For instance, chandelier cells, arcade cells, or small basket cells were not included in the present results. Therefore, we can assume that some discrepancy may be derived from a sampling bias in terms of nonpyramidal cell subtypes.

Our data demonstrate a thalamocortical origin for the vast majority of asymmetrical synapses onto double-innervated spine heads. Because the frontal cortex receives input from several thalamic nuclei, it will be important to determine whether spinous inhibition is associated with specific subsets of thalamocortical inputs. In layer IV of cat visual cortex, 2 of $31(\sim 6 \%)$ spines contacted by a genicurocortical thalamic afferent are double innervated by a symmetrical synapse (Dehay et al., 1991). A similar result was reported in rat prefrontal cortex for afferents from the mediodorsal nucleus of the thalamus (Kuroda et al., 2004). Although their sampling number is small, together, these results suggest that only a small fraction of thalamocortical boutons form synaptic connections onto double-innervated spines. This corresponds well with our finding that 9.3\% of VGLUT2innervated spines in layer IV have a second GABAergic innervation (Table 1). Together, these data suggest that shunting inhibition is important for a subpopulation of thalamocortical inputs. In the rat medial prefrontal cortex, approximately half of VGLUT2-positive afferents arise from various thalamic relay nuclei (the specific thalamocortical connection), whereas the other half derive from midline and interlaminar nuclei (the nonspecific thalamocortical connection) (Hur and Záborszky, 2005). Our observation of double-innervated spines throughout all cortical layers suggests that at least some of these spines are innervated by nonspecific inputs, whereas data from Dehay et al. (1991) and Kuroda et al. (2004) show directly that specific thalamocortical

Table 2. Spine volume and synaptic junction area of VGLUT1- and VGLUT2-innervated spines

\begin{tabular}{|c|c|c|c|c|c|}
\hline Data are mean $\pm S D$ & All spine & SI spine & Dl spine & PE spine & NP spine \\
\hline \multicolumn{6}{|l|}{$\mathrm{T} 1$} \\
\hline Spine volume $\left(\mu \mathrm{m}^{3}\right)$ & $0.073 \pm 0.060$ & $0.070 \pm 0.056$ & $0.139 \pm 0.146$ & $0.159 \pm 0.059$ & $0.048 \pm 0.032$ \\
\hline Synapse area $\left(\mu \mathrm{m}^{2}\right)$ & $0.098 \pm 0.081$ & $0.095 \pm 0.078$ & $0.182 \pm 0.170$ & $0.217 \pm 0.081$ & $0.064 \pm 0.039$ \\
\hline$n$ & 49 & 47 & 2 & 11 & 38 \\
\hline \multicolumn{6}{|l|}{$\mathrm{T} 2$} \\
\hline Spine volume $\left(\mu \mathrm{m}^{3}\right)$ & $0.143 \pm 0.071$ & $0.130 \pm 0.071$ & $0.159 \pm 0.068$ & $0.161 \pm 0.067$ & $0.121 \pm 0.070$ \\
\hline Synapse area $\left(\mu \mathrm{m}^{2}\right)$ & $0.158 \pm 0.067$ & $0.164 \pm 0.071$ & $0.148 \pm 0.060$ & $0.189 \pm 0.062$ & $0.120 \pm 0.053$ \\
\hline$n$ & 90 & 55 & 35 & 49 & 41 \\
\hline
\end{tabular}

$\mathrm{SI}$, Single innervated; DI, double innervated; NP, nonperforated synapse; PE, perforated synapse. 
Table 3. Spine subtypes with the different synaptic junction type

\begin{tabular}{|c|c|c|c|c|c|c|c|c|c|c|}
\hline \multirow[b]{3}{*}{ Layer } & \multicolumn{5}{|c|}{ VGLUT1 } & \multicolumn{5}{|c|}{ VGLUT2 } \\
\hline & \multirow[b]{2}{*}{ NP } & \multicolumn{3}{|l|}{ PE } & \multirow[b]{2}{*}{ Total } & \multirow[b]{2}{*}{ NP } & \multicolumn{3}{|l|}{ PE } & \multirow[b]{2}{*}{ Total } \\
\hline & & $P E$ & U & TJ & & & $\mathrm{PE}$ & U & TJ & \\
\hline I & 9 & 4 & 1 & 0 & 14 & 19 & 5 & 3 & 1 & 28 \\
\hline$\|/ I\|$ & 2 & 2 & 0 & 0 & 4 & 5 & 5 & 4 & 1 & 15 \\
\hline IV & 2 & 1 & 0 & 0 & 3 & 1 & 4 & 0 & 0 & 5 \\
\hline V & 20 & 2 & 1 & 0 & 23 & 7 & 9 & 3 & 1 & 20 \\
\hline VI & 5 & $\begin{array}{l}0 \\
11(22.4\end{array}$ & 0 & 0 & 5 & 9 & $\begin{array}{c}6 \\
49(54 .\end{array}$ & 6 & 1 & 22 \\
\hline Total & 38 & 9 & 2 & 0 & 49 & 41 & 29 & 16 & 4 & 90 \\
\hline & $77.6 \%$ & $18.4 \%$ & $4.1 \%$ & $0 \%$ & $100 \%$ & $45.6 \%$ & $32.2 \%$ & $17.8 \%$ & $4.4 \%$ & $100 \%$ \\
\hline
\end{tabular}

NP, Nonperforated synapse; PE, perforated synapse; U, U-shaped synapse; TJ, twin-junctional synapse.

fibers synapse onto double-innervated spines. However, the relative contribution of specific and nonspecific thalamocortical afferents onto double-innervated spines remains to be determined.

We confirmed that symmetrical synaptic inputs onto VGLUT2-receptive double-innervated spines are GABAergic. Conversely, we did not perform GABA immunohistochemistry on VGLUT1associated double-innervated spine heads attributable to their low frequency of occurrence $(0.7 \%$ of VGLUT1-receptive spines). However, because VGLUT2assocated spines were always GABAergic and because a proportion of symmetrical synapses onto spines are not GABAergic in origin [for instance, dopaminergic terminals form synapses onto spines in the frontal cortex (Carr and Sesack, 2000)], we can assume that some symmetrical synaptic junctions onto spines receiving intracortical (VGLUT1-positive) excitatory input are non-GABAergic neuromodulatory inputs.

Our results indicate that GABA inhibitory input to the cortex frequently occurs in distal segments of target cells, including spine heads, in which inhibition would be important in regulating the integration of synaptic inputs and may be able to preferentially gate thalamic input, and the involvement in double-innervated spine arrangements is a general property of all nonpyramidal cell subtypes. Because decreased inhibition onto dendrites promotes epileptic seizures (Cossart et al., 2001), gating of thalamocortical synapses with synaptic inhibition may be important in regulating excitatory dendritic drive. Strong thalamic input during whisker stimulation increases the number of double-innervated spines in somatosensory cortex (Knott et al., 2002). This may indicate that inhibitory GABAergic input on the double-innervated spines is dynamic and can adapt to changes in the level of thalamic input.
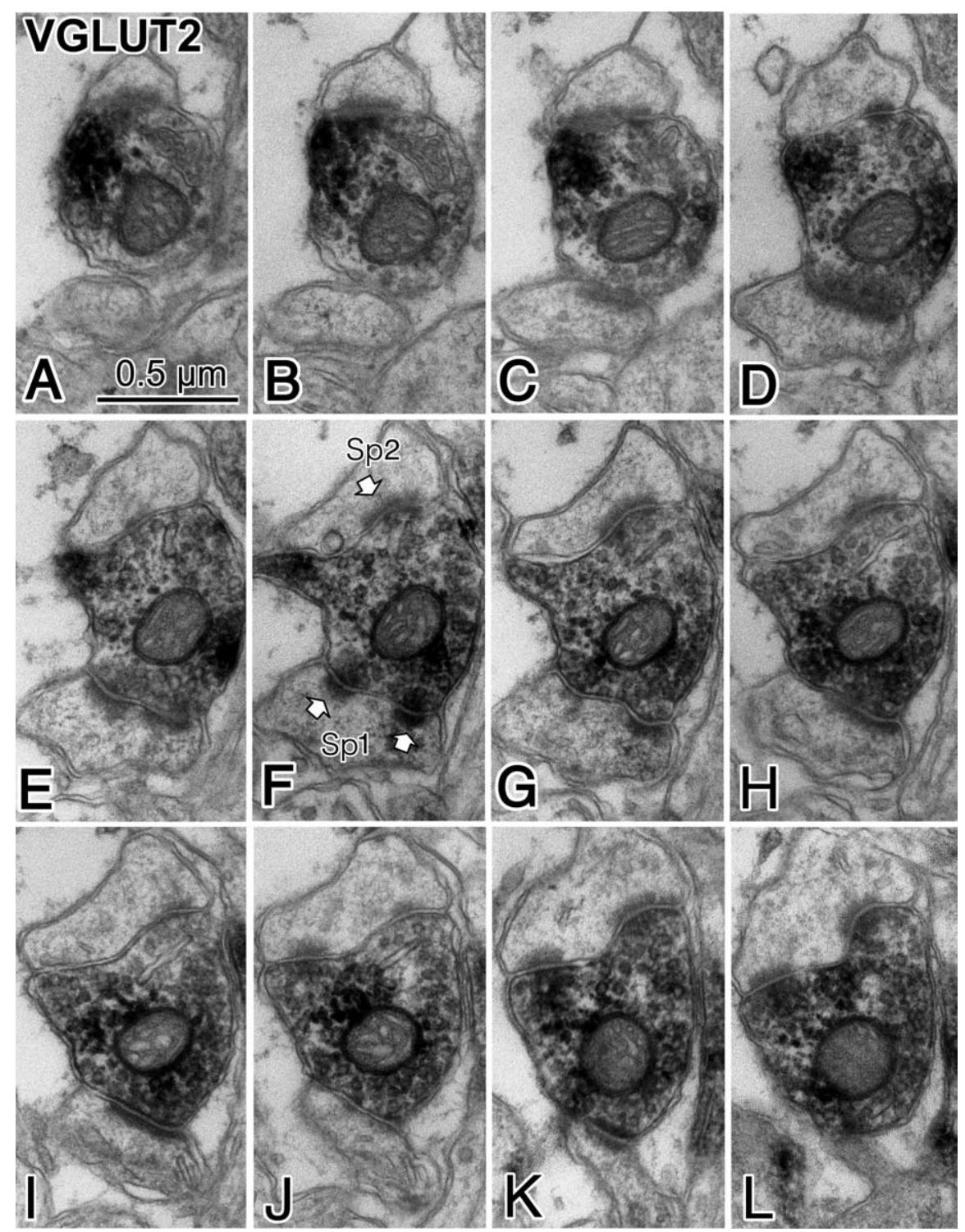

Figure 10. Electron micrograph showing a perforate synapse (Sp1) corresponding with 3D image "T2 PE" shown in Figure $9 C$. $A-L$, Successive ultrathin sections of an entire spine head (Sp1) that was innervated by a VGLUT2-positive axon terminal. An asymmetrical synapse was observed, and the middle of the successive ultrathin sections postsynaptic junction was split in two parts $(\boldsymbol{E}-\boldsymbol{G})$ and again merged together, indicating a typical perforated synapse. A second synapse (Sp2) formed by the VGLUT2positive axon terminal (onto different postsynaptic target) is also a perforated synapse because the postsynaptic density is split into two parts in $\boldsymbol{J}-\boldsymbol{L}$. 


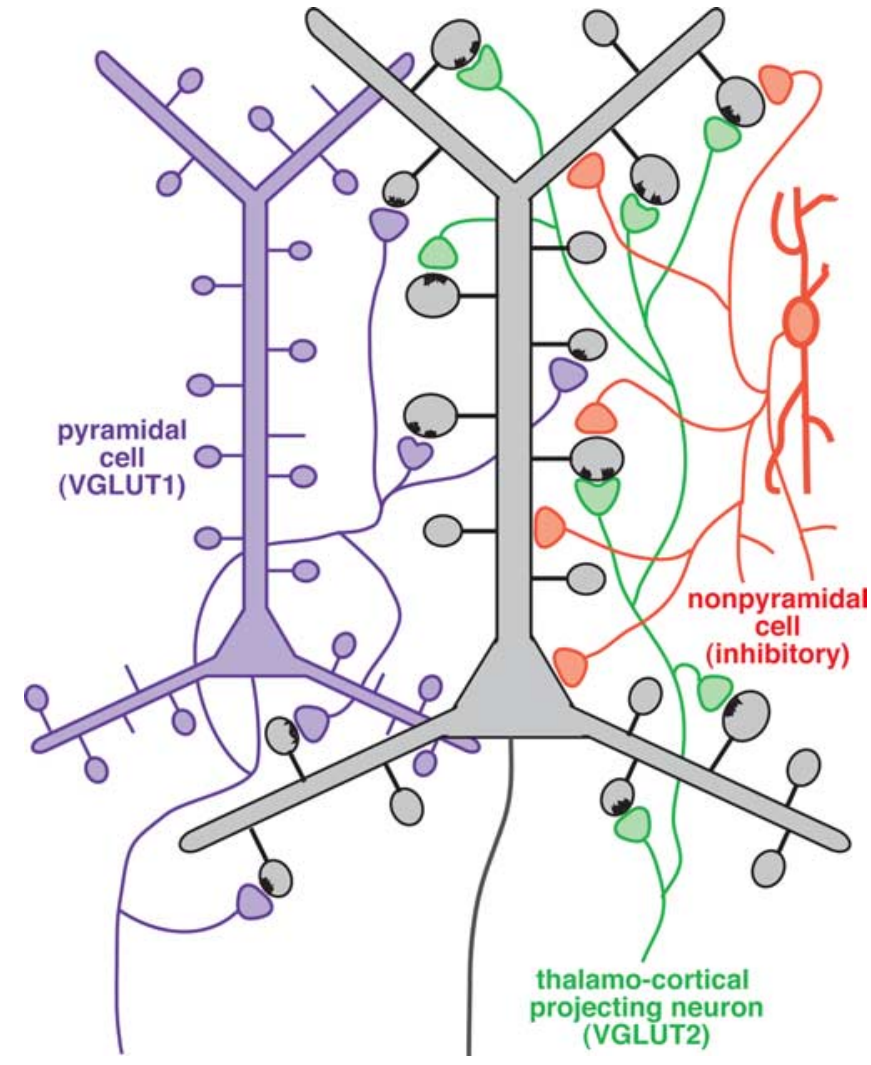

Figure 11. Schematic summary of the GABAergic input to dendritic spines. Most VGLUT1positive axon terminals originate from cortical cells (purple) and innervate spines of cortical pyramidal neurons (gray) that receive no secondary synaptic input. VGLUT2-positive axon terminals (green) originate from the thalamus and innervate larger spine heads of pyramidal cells (gray) that exhibit a second, GABAergic synaptic input (orange) in $\sim 10 \%$ of cases.

Thalamic afferents to double-innervated spines are likely high-efficacy synapses given the large size of their postsynaptic spines and AMPA receptor localization at the synaptic junction. Therefore, one potential physiological significance of GABA innervation to these spines may be to decouple strong thalamic inputs to cortical pyramidal neurons via local shunting inhibition at the spine itself. Given that interneuron subgroups tend to project to different dendritic sites on pyramidal neurons (Buhl et al., 1994; Kawaguchi and Kubota, 1998; Somogyi et al., 1998; Támas et al., 2003; Markram et al., 2004), and our data showing that spinous inhibition to pyramidal neurons is provided by many different classes of interneuron, it remains to be determined whether different thalamic inputs are inhibited by specific classes of interneurons, perhaps in a location-dependent manner within the dendritic tree. This question should be investigated in the near future.

Finally, our data finding significant differences in the size of spines innervated by VGLUT1- and VGLUT2-positive terminals correspond with data from the amygdala, in which spines innervated by thalamic afferents are larger than those innervated by cortical afferents (Humeau et al., 2005). Recent imaging studies indicate that spines become enlarged after the induction of longterm potentiation but shrink when synapses undergo long-term depression (Matsuzaki et al., 2004; Okamoto et al., 2004; Zhou et al., 2004) and that only larger spines incorporate AMPA receptors (Takumi et al., 1999; Matsuzaki et al., 2001; Nicholson et al., 2006). Our results demonstrate that spines receiving VGLUT2positive inputs, presumably thalamocortical terminals, are ap- proximately twice as large as those receiving VGLUT1-positive inputs, corticocortical terminals (Fig. 9), and that these terminals express AMPA receptors (Fig. 8E). This suggests that thalamocortical inputs are stronger, more reliable, and less plastic than corticocortical inputs (Crair and Malenka, 1995; Stratford et al., 1996; Gil et al., 1999). Recent data from dual recordings of thalamocortical connections in vivo show thalamocortical synapses have low efficacy in depolarizing cortical neurons (Bruno and Sakmann, 2006), a result that may reflect electrotonic differences in synapse localization or the impact of feedforward inhibition onto thalamocortical receptive spines.

Together, these findings add new depth to our understanding of cortical circuitry and suggest that similar mechanisms may allow GABAergic or other neuromodulatory inputs to regulate specific subsets of excitatory inputs to the cortex. A full understanding of how axon terminals identify appropriate subsets of spines from the many available targets will provide critical insight into how information is processed in cortical microcircuits.

\section{References}

Agmon A, Yang LT, O’Dowd DK, Jones EG (1993) Organized growth of thalamocortical axons from the deep tier of terminations into layer IV of developing mouse barrel cortex. J Neurosci 13:5365-5382.

Beaulieu C, Kisvárday Z, Somogyi P, Cynader M, Cowey A (1992) Quantitative distribution of GABA-immunopositive and -immunonegative neurons and synapses in the monkey striate cortex (area 17). Cereb Cortex 2:295-309.

Berendse HW, Groenewegen HJ (1991) Restricted cortical termination fields of the midline and intralaminar thalamic nuclei in the rat. Neuroscience 42:73-102.

Bruno RM, Sakmann B (2006) Cortex is driven by weak but synchronously active thalamocortical synapses. Science 312:1622-1627.

Buhl EH, Halasy K, Somogyi P (1994) Diverse sources of hippocampal unitary inhibitory postsynaptic potentials and the number of synaptic release sites. Nature 368:823-828.

Carr DB, Sesack SR (2000) Dopamine terminals synapse on callosal projection neurons in the rat prefrontal cortex. J Comp Neurol 425:275-283.

Cossart R, Dinocourt C, Hirsch JC, Merchan-Perez A, DeFelipe J, Ben-Ari Y, Esclapez M, Bernard C (2001) Dendritic but not somatic GABAergic inhibition is decreased in experimental epilepsy. Nat Neurosci 4:52-62.

Crair MC, Malenka RC (1995) A critical period for long-term potentiation at thalamocortical synapses. Nature 375:325-328.

De Gois S, Schafer MK, Defamie N, Chen C, Ricci A, Weihe E, Varoqui H, Erickson JD (2005) Homeostatic scaling of vesicular glutamate and GABA transporter expression in rat neocortical circuits. J Neurosci 25:7121-7133.

Dehay C, Douglas RJ, Martin KA, Nelson C (1991) Excitation by geniculocortical synapses is not "vetoed" at the level of dendritic spines in cat visual cortex. J Physiol (Lond) 440:723-734.

Donoghue JP, Wise SP (1982) The motor cortex of the rat: cytoarchitecture and microstimulation mapping. J Comp Neurol 212:76-88.

Fremeau Jr RT, Troyer MD, Pahner I, Nygaard GO, Tran CH, Reimer RJ, Bellocchio EE, Fortin D, Storm-Mathisen J, Edwards RH (2001) The expression of vesicular glutamate transporters defines two classes of excitatory synapse. Neuron 31:247-260.

Fujiyama F, Furuta T, Kaneko T (2001) Immunocytochemical localization of candidates for vesicular glutamate transporters in the rat cerebral cortex. J Comp Neurol 435:379-387.

Gil Z, Connors BW, Amitai Y (1999) Efficacy of thalamocortical and intracortical synaptic connections: quanta, innervation, and reliability. Neuron 23:385-397.

Groenewegen HJ (1988) Organization of the afferent connections of the mediodorsal thalamic nucleus in the rat, related to the mediodorsalprefrontal topography. Neuroscience 24:379-431.

Gulledge AT, Stuart GJ (2003) Excitatory actions of GABA in the cortex. Neuron 37:299-309.

Humeau Y, Herry C, Kemp N, Shaban H, Fourcaudot E, Bissiere S, Luthi A (2005) Dendritic spine heterogeneity determines afferent-specific Hebbian plasticity in the amygdala. Neuron 45:119-131.

Hur EE, Záborszky L (2005) Vglut2 afferents to the medial prefrontal and 
primary somatosensory cortices: a combined retrograde tracing in situ hybridization. J Comp Neurol 483:351-373.

Jones EG (1998) A new view of specific and nonspecific thalamocortical connections. Adv Neurol 77:49-71; discussion 72-43.

Jones EG, Powell TP (1969) Morphological variations in the dendritic spines of the neocortex. J Cell Sci 5:509-529.

Karube F, Kubota Y, Kawaguchi Y (2004) Axon branching and synaptic bouton phenotypes in GABAergic nonpyramidal cell subtypes. J Neurosci 24:2853-2865.

Kawaguchi Y, Kondo S (2002) Parvalbumin, somatostatin and cholecystokinin as chemical markers for specific GABAergic interneuron types in the rat frontal cortex. J Neurocytol 31:277-287.

Kawaguchi Y, Kubota Y (1993) Correlation of physiological subgroupings of nonpyramidal cells with parvalbumin- and calbindin D28kimmunoreactive neurons in layer $\mathrm{V}$ of rat frontal cortex. J Neurophysiol 70:387-396.

Kawaguchi Y, Kubota Y (1997) GABAergic cell subtypes and their synaptic connections in rat frontal cortex. Cereb Cortex 7:476-486.

Kawaguchi Y, Kubota Y (1998) Neurochemical features and synaptic connections of large physiologically-identified GABAergic cells in the rat frontal cortex. Neuroscience 85:677-701.

Kawaguchi Y, Karube F, Kubota Y (2006) Dendritic branch typing and spine expression patterns in cortical nonpyramidal cells. Cereb Cortex 16:696-711.

Kisvárday ZF, Martin KA, Friedlander MJ, Somogyi P (1987) Evidence for interlaminar inhibitory circuits in the striate cortex of the cat. J Comp Neurol 260:1-19.

Klausberger T, Magill PJ, Marton LF, Roberts JD, Cobden PM, Buzsaki G, Somogyi P (2003) Brain-state- and cell-type-specific firing of hippocampal interneurons in vivo. Nature 421:844-848.

Klausberger T, Marton LF, Baude A, Roberts JD, Magill PJ, Somogyi P (2004) Spike timing of dendrite-targeting bistratified cells during hippocampal network oscillations in vivo. Nat Neurosci 7:41-47.

Klausberger T, Marton LF, O’Neill J, Huck JH, Dalezios Y, Fuentealba P, Suen WY, Papp E, Kaneko T, Watanabe M, Csicsvari J, Somogyi P (2005) Complementary roles of cholecystokinin- and parvalbumin-expressing GABAergic neurons in hippocampal network oscillations. J Neurosci 25:9782-9793.

Knott GW, Quairiaux C, Genoud C, Welker E (2002) Formation of dendritic spines with GABAergic synapses induced by whisker stimulation in adult mice. Neuron 34:265-273.

Kubota Y, Hattori R, Yui Y (1994) Three distinct subpopulations of GABAergic neurons in rat frontal agranular cortex. Brain Res 649:159-173.

Kuroda M, Yokofujita J, Oda S, Price JL (2004) Synaptic relationships between axon terminals from the mediodorsal thalamic nucleus and gamma-aminobutyric acidergic cortical cells in the prelimbic cortex of the rat. J Comp Neurol 477:220-234.

Markram H, Toledo-Rodriguez M, Wang Y, Gupta A, Silberberg G, Wu C (2004) Interneurons of the neocortical inhibitory system. Nat Rev Neurosci 5:793-807.

Matsuzaki M, Ellis-Davies GC, Nemoto T, Miyashita Y, Iino M, Kasai H (2001) Dendritic spine geometry is critical for AMPA receptor expression in hippocampal CA1 pyramidal neurons. Nat Neurosci 4:1086-1092.

Matsuzaki M, Honkura N, Ellis-Davies GC, Kasai H (2004) Structural basis of long-term potentiation in single dendritic spines. Nature 429:761-766.

Meskenaite V (1997) Calretinin-immunoreactive local circuit neurons in area 17 of the cynomolgus monkey, Macaca fascicularis. J Comp Neurol 379:113-132.

Morishima M, Kawaguchi Y (2006) Recurrent connection patterns of corticostriatal pyramidal cells in frontal cortex. J Neurosci 26:4394-4405.

Nicholson DA, Trana R, Katz Y, Kath WL, Spruston N, Geinisman Y (2006) Distance-dependent differences in synapse number and AMPA receptor expression in hippocampal CA1 pyramidal neurons. Neuron 50:431-442.

Nusser Z, Sieghart W, Benke D, Fritschy JM, Somogyi P (1996) Differential synaptic localization of two major gamma-aminobutyric acid type A receptor alpha subunits on hippocampal pyramidal cells. Proc Natl Acad Sci USA 93:11939-11944.

Okamoto K, Nagai T, Miyawaki A, Hayashi Y (2004) Rapid and persistent modulation of actin dynamics regulates postsynaptic reorganization underlying bidirectional plasticity. Nat Neurosci 7:1104-1112.

Paxinos G, Watson C (1998) The rat brain in stereotaxic coordinates, Ed 4. San Diego: Academic.

Porter LL, White EL (1986) Synaptic connections of callosal projection neurons in the vibrissal region of mouse primary motor cortex: an electron microscopic/horseradish peroxidase study. J Comp Neurol 248:573-587.

Schaeren-Wiemers N, Andre E, Kapfhammer JP, Becker-Andre M (1997) The expression pattern of the orphan nuclear receptor RORbeta in the developing and adult rat nervous system suggests a role in the processing of sensory information and in circadian rhythm. Eur J Neurosci 9:2687-2701.

Skoglund TS, Pascher R, Berthold CH (1997) The existence of a layer IV in the rat motor cortex. Cereb Cortex 7:178-180.

Somogyi P, Támas G, Lujan R, Buhl EH (1998) Salient features of synaptic organisation in the cerebral cortex. Brain Res Brain Res Rev 26:113-135.

Stratford KJ, Tarczy-Hornoch K, Martin KA, Bannister NJ, Jack JJ (1996) Excitatory synaptic inputs to spiny stellate cells in cat visual cortex. Nature 382:258-261.

Takumi Y, Ramirez-Leon V, Laake P, Rinvik E, Ottersen OP (1999) Different modes of expression of AMPA and NMDA receptors in hippocampal synapses. Nat Neurosci 2:618-624.

Tamás G, Buhl EH, Somogyi P (1997) Fast IPSPs elicited via multiple synaptic release sites by different types of GABAergic neurone in the cat visual cortex. J Physiol (Lond) 500:715-738.

Tamás G, Lörincz A, Simon A, Szabadics J (2003) Identified sources and targets of slow inhibition in the neocortex. Science 299:1902-1905.

Thomson AM, West DC, Wang Y, Bannister AP (2002) Synaptic connections and small circuits involving excitatory and inhibitory neurons in layers $2-5$ of adult rat and cat neocortex: triple intracellular recordings and biocytin labelling in vitro. Cereb Cortex 12:936-953.

Watts J, Thomson AM (2005) Excitatory and inhibitory connections show selectivity in the neocortex. J Physiol (Lond) 562:89-97.

Wu Y, Kawakami R, Shinohara Y, Fukaya M, Sakimura K, Mishina M, Watanabe M, Ito I, Shigemoto R (2005) Target-cell-specific left-right asymmetry of NMDA receptor content in Schaffer collateral synapses in epsilon1/NR2A knock-out mice. J Neurosci 25:9213-9226.

Yoshimura Y, Callaway EM (2005) Fine-scale specificity of cortical networks depends on inhibitory cell type and connectivity. Nat Neurosci 8:1552-1559.

Yoshimura Y, Dantzker JL, Callaway EM (2005) Excitatory cortical neurons form fine-scale functional networks. Nature 433:868-873.

Zhou Q, Homma KJ, Poo MM (2004) Shrinkage of dendritic spines associated with long-term depression of hippocampal synapses. Neuron 44: 749-757. 